This is the peer reviewed version of the following article: Vrij, A., Fisher, R. P. and

Blank, H. (2015), A cognitive approach to lie detection: A meta-analysis. Legal and Criminological Psychology. doi: 10.1111/lcrp.12088, which has been published in final form at http://onlinelibrary.wiley.com/doi/10.1111/lcrp.12088/full . This article may be used for non-commercial purposes in accordance with Wiley Terms and Conditions for

\title{
Self-Archiving.
}

\section{A Cognitive Approach to Lie Detection: A Meta-Analysis}

\author{
Aldert Vrij ${ }^{1}$ \\ University of Portsmouth \\ Ronald P. Fisher \\ Florida International University \\ Hartmut Blank \\ University of Portsmouth
}

\footnotetext{
${ }^{1}$ Correspondence concerning this article should be addressed to: Aldert Vrij, University of Portsmouth, Psychology Department, King Henry Building, King Henry 1 Street, Portsmouth, PO1 2DY, United Kingdom or via email: aldert.vrij@ port.ac.uk.
} 


\begin{abstract}
Introduction. This article provides a meta-analysis of a new, cognitive, approach to (non)verbal lie detection. This cognitive lie detection approach consists of three techniques, (i) imposing cognitive load, (ii) encouraging interviewees to say more and (iii) asking unexpected questions.
\end{abstract}

Method. A meta-analysis was carried out on studies using the cognitive approach, 14 of which directly compared the cognitive approach to a standard approach.

Results. The cognitive lie detection approach produced superior accuracy results in truth detection (67\%), lie detection (67\%) and total detection (truth and lie detection combined, $71 \%$ ) compared to a traditional standard approach (truth detection: 57\%; lie detection: 47\%; total detection: $56 \%)$.

Conclusions. Practitioners may find it useful to use a cognitive lie detection approach in their daily practice. 


\section{A Cognitive Approach to Lie Detection: A Meta Analysis}

This article provides a meta-analysis of a new, cognitive, approach to (non)verbal lie detection. The starting point of this approach is Zuckerman, DePaulo and Rosenthal's (1981) early observation that lying can be more mentally taxing than telling the truth. The new aspect is that investigators can magnify the difference in cognitive load that liars and truth tellers experience through specific interventions. The interviewing techniques discussed in this article focus on lie detection through observing someone's behaviour or listening to someone's speech when no other relevant background information is available. Such veracity judgements are frequently made and result in low accuracy rates (54\% on average according to Bond and DePaulo's, 2006, meta-analysis). For verbal lie detection when background information is available, see the Strategic Use of Evidence technique (Granhag \& Hartwig, 2008, 2015; Hartwig, Granhag, \& Luke, 2014).

Reviews of the cognitive lie detection approach have been published before (Vrij, 2014, 2015; Vrij \& Granhag, 2012; Vrij, Granhag, Mann, \& Leal, 2011; Vrij, Granhag, \& Porter, 2010; Vrij, Leal, Mann, Vernham, \& Brankaert, 2015). The main difference between this article and the previous articles is that this article expands the literature by reporting a meta-analysis examining whether the cognitive lie detection approach facilitates lie detection. The focus of this article is entirely on the meta-analysis. Elsewhere we describe in detail 'theories about lying and cognition' (Vrij, 2014), why and when liars experience more cognitive load than truth tellers in interview settings (Vrij, 2015), and the empirical evidence that liars do often experience more cognitive loads than truth tellers in interview settings (Vrij, 2015).

\section{Cognitive Lie Detection:}




\section{Enhancing the Differences in Cognitive Cues between Truth Tellers and Liars}

The core of the cognitive lie detection approach is that investigators can magnify the differences in (non)verbal cues indicative of cognitive load displayed by truth tellers and liars through interventions based on cognitive principles that makes the liars' task even more cognitively demanding. If successful, those interventions should result in liars displaying more diagnostic cognitive cues to deception and thereby facilitating lie detection. The cognitive lie detection approach consists of three techniques that can differentiate truth tellers from liars: (i) Imposing cognitive load, (ii) encouraging interviewees to provide more information, and (iii) asking unexpected questions.

\section{Imposing Cognitive Load}

Imposing cognitive load is based on the well established empirical finding that in interview settings lying is typically more mentally taxing than truth telling (see for example fMRI research, Christ et al. 2009; Vrij \& Ganis, 2014). Imposing cognitive load refers to investigators' interventions aimed at making the interview setting mentally more difficult. Liars, who often require more cognitive resources than truth tellers in interviews settings, will have fewer cognitive resources left over. If cognitive demand is further raised, which could be achieved by making additional requests, liars may be less able than truth tellers to cope with these additional requests.

Ways to impose cognitive load is by asking interviewees to tell their stories in reverse order (e.g., Evans, Meissner, Michael, \& Brandon, 2013; Vrij, Leal, Mann, \& Fisher, 2012; Vrij et al., 2008; Zimmerman et al., 2010); by instructing interviewees to maintain eye contact with the interviewer (Vrij, Mann, Leal, \& Fisher, 2010); by asking interviewees to carry out two tasks simultaneously (e.g., story telling while gripping an 
object, Debey, Verschuere, \& Crombez, 2012; Visu-Petra, Varga, Miclea, \& Visu-Petra, 2013); or through forced turn-taking which can be employed when two or more interviewees are interviewed together at the same time (Vernham, Vrij, Mann, Leal, \& Hillman, 2014). In forced turn-taking, after asking the question, the investigator determines who starts answering a question. The investigator then interrupts that person after a short period of time and asks a second interviewee to continue with the story. After a short period of time, that person is interrupted and the third person (or the first person again in case of interviewing a pair) is asked to continue, etc.

\section{Encouraging Interviewees to Provide More Information}

The second technique that may differentiate truth tellers from liars is encouraging interviewees to provide more information. If truth tellers provide more information they are more likely to be believed, because the richer an account is perceived to be in detail, the more likely it is to be believed (Bell \& Loftus, 1989; Johnson, 2006; Johnson, Foley, Suengas, \& Raye, 1988). Moreover, the additional information truth tellers provide could provide leads to investigators to check. Liars may find it cognitively too difficult to add as many details as truth tellers do, or, if liars do add a sufficient amount of detail, the additional information may be of lesser quality or may sound less plausible. Also, liars may be reluctant to add more information out of fear that it will provide leads to investigators and, consequently, give their lies away. In other words, techniques that facilitate interviewees to say more may result in truth tellers in particular saying more. Research has supported this premise. Experimental research to date has revealed four ways to facilitate truth tellers to say more: by using a supportive interviewer (nodding head and smiling during an interview, Mann et al., 2013; Shaw, Vrij, Mann, Leal, \& 
Hillman, 2013), by giving an example of a model answer (a very detailed answer, Bogaard, Meijer, \& Vrij, 2014; Leal, Vrij, Warmelink, \& Fisher, 2015), by using drawings (e.g., Vrij, Leal, et al., 2010; Vrij, Mann, Leal, \& Fisher, 2012), and by using the Cognitive Interview technique (Ansarra et al., 2011; Bembibre \& Higueras, 2011, 2012; Colwell, Hiscock, \& Memon, 2002; Colwell, Hiscock-Anisman, Memon, Rachel, \& Colwell, 2007; Colwell, Hiscock-Anisman, Memon, Taylor, \& Prewett, 2007; Colwell, Hiscock-Anisman, Memon, Colwell, Taylor, \& Woods, 2009; Geiselman, 2012; Hernandez-Fernaud \& Alonso-Quecuty, 1997; Köhnken, Schimossek, Aschermann, \& Höfer, 1995; Memon, Fraser, Colwell, Odinot, \& Mastroberardino, 2010; Morgan, Colwell, Hazlett, 2011; Parker \& Brown, 2000; Suckle-Nelson et al., 2010).

\section{Asking Unexpected Questions}

A consistent finding in the deception literature is that liars prepare themselves for anticipated interviews. They do so by preparing possible answers to questions they expect to be asked (Granhag, Andersson, Strömwall, \& Hartwig, 2004; Granhag, Strömwall, \& Jonsson, 2003; Hartwig, Granhag, \& Strömwall, 2007; Vrij et al., 2009).

This strategy of preparing answers for possible questions makes sense. Planning makes lying easier -thereby combating, to some degree, the additional cognitive demand of lying- and planned lies typically contain fewer cues to deceit than spontaneous lies (DePaulo et al., 2003). However, preparing for answers has a limitation. It will be fruitful only if liars correctly anticipate which questions will be asked. Investigators can exploit this limitation by asking questions that liars do not anticipate. Though liars can refuse to answer unexpected questions by saying "I don't know" or "I can't remember", such responses will create suspicion if these questions are about central aspects of the target 
event. A liar, therefore, has little option other than to fabricate a plausible answer on the spot, which is cognitively demanding. For liars, expected questions should be easier to answer than unexpected questions, because liars can give their planned and rehearsed answers to the expected questions but they need to fabricate answers to the unexpected questions. The difference liars experience in cognitive load while answering these two sets of questions should become evident in their verbal responses. In contrast, truth tellers experience similar levels of cognitive load while answering expected and unexpected questions, and they should produce more comparable answers to the expected and unexpected questions than liars.

To date, in the unexpected-questions technique, comparisons between truth tellers and liars have been made in three different manners, each of which examines a different outcome measure (e.g., dependent variable). In a first set of studies, small groups of truth tellers who went on a mission together and small groups of liars who had fabricated a story about going on a mission together were interviewed separately. In the interview they were asked a mixture of expected and unexpected questions (for example general opening questions versus spatial questions, Vrij et al., 2009), and the answers given by the different individuals belonging to a group were compared to one another (Roos af Hjelmsäter, Ohman, Granhag, \& Vrij, 2014; Sooniste, Granhag, Strömwall, \& Vrij, in press; Vrij et al., 2009).

In a second set of studies individual truth tellers and liars took part and were asked a mixture of expected and unexpected questions, for example about the execution (expected) or planning (unexpected) of intentions (Granhag \& Knieps, 2011). Differences between truth tellers and liars in answering the two types of question were examined (Granhag \& 
Knieps, 2011; Knieps, Granhag, \& Vrij, 2013a, b; Lancaster, Vrij, Hope, \& Waller, 2012;

Liu et al., 2010; Mac Giolla \& Granhag, 2014; Shaw, Vrij, Mann, Leal, \& Hillman, 2013;

Sooniste, Granhag, Knieps, \& Vrij, 2013; Vrij, Leal, Mann, \& Granhag, 2011;

Warmelink, Vrij, Mann, Jundi, \& Granhag, 2012).

In a third set of studies individual truth tellers and liars were interviewed and were asked the same unexpected question twice, albeit in a different format (verbal recall vs sketching). The overlap in the two answers was examined (Leins, Fisher, Vrij, 2012; Leins, Fisher, Vrij, \& Mann, 2011).

\section{A Quantitative Review of the Cognitive Lie Detection Approach}

Having introduced the cognitive lie detection approach above, the natural question to ask is: How effective is this approach compared to a standard lie detection approach? In this section, we present a meta-analysis of studies that compared the two approaches. We meta-analytically integrate accuracy rates and effect sizes and test the hypothesis that the cognitive load lie detection approach facilitates truth and lie detection. Moreover, data from additional studies that did not directly compare a standard with a cognitive lie detection approach but used the cognitive lie detection approach only will be used to precise the accuracy estimates from the direct comparison studies.

\section{Method}

Overview. We calculated effect sizes reflecting the difference in accuracy rates obtained with the standard and cognitive lie detection approaches and then integrated these effect sizes following standard meta-analytic methodology (Cooper \& Hedges, 1994; Hedges \& Olkin, 1985). We did this separately for truth detection accuracy, lie 
detection accuracy and total accuracy (i.e., truth and lie detection combined), and using two different measures of effect size, odds ratios and Cohen's $d s .{ }^{1}$ Initial analyses covered estimates and statistical significance of the population effect sizes, assessments of effect size heterogeneity and fail-safe $\mathrm{N}$ analyses (as a rough indicator of potential publication bias). For both the odds ratio-based and the $d$-based meta-analyses, we used a random effects approach as recommended in the meta-analytic literature (e.g. Borenstein, Hedges \& Rothstein, 2007). This approach assumes that there is not necessarily one fixed, 'true' effect size in the population but that the population effect size may vary as a function of differences in study design, participants, materials or procedures (which are treated as random variations). Subsequent moderator analyses explored if the effectiveness of the cognitive lie detection approach depends (1) on whether veracity classifications are based on participants' judgments or on objective criteria and (2) on the type of cognitive lie detection manipulation (imposing load, encouraging interviewees to say more, asking unexpected questions). Participants' judgements may give us an idea how accurate observers are in truth - lie classifications when being exposed to interviews where the cognitive approach was implemented but such judgements create noise, for example when observers focus on non-diagnostic cues or interpret the diagnostic cues incorrectly. Objective criteria classifications give us a better idea of the potential of the cognitive lie detection approach.

Included studies. We searched for relevant studies in Psyclit, Psycinfo, Google Scholar and Web of Knowledge by using combinations of key words such as 'deception', 'lie', 'lying', 'detection', 'cognitive load', and 'interviewing'. We also contacted the leading scholars (Colwell, Granhag, and Meissner) who are heads of their research 
groups and active in this research area, and checked the websites of journals that have published work in this area (Applied Cognitive Psychology, Journal of Applied Research in Memory and Cognition, Law and Human Behavior, Legal and Criminological Psychology, Psychology, Crime, \& Law). Inclusion criteria were (1) that a study had to employ some form of cognitive lie detection manipulation (imposing cognitive load, encouraging interviewees to report more, or asking unexpected questions) and (2) that it reported some measure(s) of accuracy of lie detection (accuracy percentages for truth detection, lie detection, or combined truth/lie detection accuracy). This resulted in 26 experimental studies (reported in 24 papers, marked with asterisks in the reference list; two papers contained two experiments each), the details of which are summarized in Appendix 1. Fourteen of these studies explicitly contrasted lie detection in a cognitive lie detection approach condition with a standard approach condition (e.g., a condition that involved no cognitive lie detection manipulation as defined above), and were therefore included in our meta-analysis.

Effect sizes and study weights. Each of the 14 direct comparison studies contributed one or three effect sizes (depending on whether they reported truth, lie and total detection accuracy or only the latter) to both the odds ratio-based and the $d$-based meta-analysis. In the odds ratio-based meta-analysis (see Haddock et al., 1998, for an introduction), the odds ratios were derived directly from the accuracy rates in two conditions. To illustrate, Colwell et al. (2002) report $62 \%$ and $76 \%$ total accuracy in the standard and cognitive lie detection approach conditions, respectively, which translates into an odds ratio of 1.94 [76\%/(100\%-76\%) divided by 62\%/(100\%-62\%)] in favour of the cognitive approach - in other words, the odds of accurate detection were almost twice 
as high with the cognitive approach. An odds ratio of 1.0 indicates no difference between conditions, and odds ratios of 3.0 or larger signals a strong effect. For the $d$-based metaanalysis, Cohen's $d$ reflected the mean difference between the accuracy rates obtained with the cognitive vs. the standard approach, divided by the common standard deviation of these rates (a statistical compromise between the standard deviations within each approach). Although some studies used a within-participants manipulation of lie detection approach, we always computed Cohen's $d$ as if it had been found in a betweenparticipants design, following the generally accepted recommendation of Dunlap, Cortina, Vaslow, and Burke (1996).

In both the odds ratio-based and the $d$-based meta-analyses, the effect sizes were obtained for each study and then meta-analytically integrated by weighting them according to sample size, whereby effect sizes from larger studies receive larger weights, as they are more reliable (being based on more observations). This is standard practice, but in the particular context of lie detection studies the issue of what should be regarded as the sample size is more complex than usual and therefore requires comment. Specifically, in some studies participant-observers watch or listen to statements by liars and/or truth tellers and then make decisions about the veracity of these statements. In other studies, veracity classifications are not made by observers but are based on objective criteria (e.g., the amount of detail in a statement) and a cut-off criterion or decision rule. Hence, the relevant sample sizes are the numbers of participant-observers (in different conditions) in the former studies and the numbers of categorized statements in the latter studies.

\section{Results}


Lie detection accuracy. Table 1 summarizes the meta-analytic integration of the accuracy rates in the studies that directly compared the standard and cognitive approach, separately for total accuracy (14 studies) and for truth and lie detection accuracy (11 out of these 14 studies). The sample sizes and accuracy rates of the individual studies are documented in the Appendix (with one single exception for truth detection [Zimmerman et al., 2010], accuracy was always higher for the cognitive approach). Table 1 shows that the cognitive lie detection approach is superior to the standard approach for all three measures of detection accuracy (truth: $67 \%$ versus $57 \%$, lie: $67 \%$ versus $47 \%$, or combined: $71 \%$ versus $56 \%$ - note that the total accuracy rate differs from the average of the truth and lie accuracy rates because it is based on all 14 studies). It is noteworthy that the $56 \%$ (total) accuracy rate obtained with a standard approach very closely approximates the typical $54 \%$ accuracy rate typically found in deception research (Bond $\&$ DePaulo, 2006), $z=1.08, p=.28$. By contrast, the $71 \%$ total accuracy rate obtained using the cognitive lie detection approach significantly exceeds this $54 \%$ accuracy benchmark, $z=9.37, p<.001$.

These differences in accuracy rates translate into small (truth accuracy) to moderate (lie and total accuracy) effect sizes in both the odds ratio-based and the $d$-based meta-analysis. Generally the findings obtained with the two meta-analytic approaches mostly coincide: The rank order of the effect sizes is the same (lie detection accuracy largest, truth smallest, total in between), and also all effect sizes differ significantly from zero (see Table 1 for the full pattern of results). The fail-safe $\mathrm{Ns}$ - the numbers of filedrawer studies with zero effects sizes needed to render the effects non-significant (Rosenthal, 1979; Rosenberg, 2005) - were comparable as well, and they indicate that 
publication bias is unlikely to be an issue here (certainly at the level of total accuracy). The most important difference between the two approaches is that the $d$-based metaanalysis indicates more heterogeneity of effect sizes (particularly for total accuracy).

Moderator analyses. Despite some non-significant heterogeneity of some of the effect sizes (see Table 1), we decided to proceed with our planned moderator analyses, as they are theoretically interesting and also sometimes moderator effects emerge in spite of statistical homogeneity of effect sizes. Our two moderator analyses checked whether the accuracy results reported in Table 1 (i) depended on how the accuracy judgements were made (by human judges or based on objective criteria, using e.g. a discriminant analysis algorithm) and (ii) if any of the cognitive lie detection techniques introduced earlier (imposing load, encouraging interviewees to say more, or asking unexpected questions) were more effective than others in terms of detection accuracy. The outcome of these moderator analyses (conducted on the basis of both odds ratios and Cohen's $d$ s) are summarised in Tables 2 and 3.

How the veracity decisions were made (by humans or based on objective criteria) did not matter very much for total accuracy, $Q_{\mathrm{B}}(1)=0.85, p=.36$. This picture changed at the level of truth and lie accuracy (see Table 2). The weighted accuracy rates and the moderator effects (based on both odds ratios and Cohen's $d \mathrm{~s}^{2}$ ) show the same basic picture. For truth detection, the cognitive lie detection approach works best when veracity decisions are based on objective criteria, but there is little advantage over the standard approach for human observers. The opposite pattern emerged for lie detection, where the human observers profited more from the cognitive lie detection approach than criteriabased lie detection. A possible explanation for these findings is that humans typically 
obtain poor lie accuracy, due to having a truth bias (the inclination to think that a target person is telling the truth, Vrij, 2008). In that respect, there is for humans more room for improvement in increasing their lie accuracy than their truth accuracy.

Our second moderator analysis explored if the effectiveness of the cognitive approach depended on the particular technique employed (imposing load, encouraging interviewees to say more, asking unexpected questions). As before, there was no significant moderator effect for total accuracy, $Q_{\mathrm{B}}(2)=1.48, p=.48$, but this was again owed to opposite moderator effects for truth and lie detection (see Table 3 ). ${ }^{3}$ For truth detection, the most effective technique was encouraging interviewees to say more, followed by asking unexpected questions and imposing load. An opposite pattern emerged for lie accuracy. The most effective lie detection technique was imposing load, followed by asking unexpected questions and encouraging interviewees to say more. This pattern nicely reflects the theoretical rationale given for the techniques. We argued that encouraging interviewees to say more would particularly encourage truth tellers to say more. Therefore, following this reasoning, truth tellers would differ most between standard and cognitive lie detection technique, which facilitates truth detection in particular. We also argued that liars in particular would face difficulties with coping with imposing cognitive load. Therefore, following this reasoning, liars would differ most between standard and cognitive lie detection conditions in this technique, which facilitates lie detection.

A potential concern with these two moderator analyses is that there was considerable overlap between the moderators - all studies that imposed load involved human observers making the veracity decisions, and all studies that encouraged 
interviewees to say more used criteria-based decisions (studies using unexpected questions were one each); this is why the patterns of effects are so similar. As a consequence, it is difficult to say which moderator is the substantial one that drives the differences in detection accuracy rates. Future meta-analyses, including more studies, may provide the answer.

Cognitive lie detection approach findings based on all 26 studies. In addition to the studies reviewed above, which directly compared the cognitive lie detection approach to a standard approach, twelve further studies (see Appendix) had been conducted using the cognitive lie detection approach but without a standard approach comparison condition. These additional studies do not provide information about the effect of the cognitive approach (the topic of investigation in this article) but still gives some indication about the detection rates that can be expected from the cognitive lie detection approach. Combining these 12 additional studies with the 14 direct comparison studies discussed above amounted to 26 cognitive lie detection approach studies reporting total accuracy rates, 20 of which further reported truth and lie detection accuracy rates. The total accuracy weighted average based on 26 studies was $74 \%(95 \% \mathrm{CI}=71 \%$, $76 \%)$; the truth detection accuracy, based on 20 studies, was $69 \%(66 \%, 73 \%)$ and the lie detection accuracy, also based on 20 studies, was $70 \%(66 \%, 73 \%)$.

Finally, we were interested in correlations between truth and lie accuracy as a function of the lie detection approach. Interestingly, the correlation between the truth and lie accuracy rates across the 11 standard approach studies was negative, $r=-.29$, but strongly positive across the 20 cognitive approach studies, $r=.52$. The difference between these two correlations was significant, $z=2.04, p=.04$. The lack of a truth bias 
and the correlational findings, taken together, suggest that the cognitive lie detection approach not only boosts detection rates overall but boosts truth and lie detection in such a way that the typical truth bias is eliminated.

\section{Summary of the meta-analytic findings on truth and lie detection accuracy.}

In sum, the meta-analytic findings confirmed the superiority of the cognitive lie detection approach. Specifically, the cognitive lie detection approach led to better total detection accuracy (71\% versus 56\%) and also into more accurate classifications of truth tellers (67\% versus $57 \%$ ) and liars (67\% versus $47 \%)$, when compared directly to a standard approach. Additional studies using the cognitive lie detection approach only led to somewhat higher detection rates $(74 \%$ overall, and $69 \%$ and $70 \%$ for truth and lie detection, respectively).

Two moderator analyses indicated that (1) human observers mostly profited from the cognitive lie detection approach in terms of lie detection, whereas criterion-based detection benefited mostly in terms of truth detection, and (2) that different cognitive techniques had different strengths in terms of truth and lie detection. Encouraging interviewees to say more facilitates truth detection in particular and imposing cognitive load facilitates lie detection in particular. Finally, descriptive and correlational findings suggested that the cognitive approach may effectively overcome the typical truth bias in veracity judgements.

\section{Discussion}

We finish this article with some concluding thoughts about the cognitive lie detection approach. We will briefly discuss the applicability of the approach by discussing interviewees' willingness to answer questions (a requirement in each lie 
detection tool that is based on the analyses of speech) and the settings in which the various techniques can be employed. We will also discuss the practical utility of the findings presented in this meta-analysis, provide an explanation as to why the increased accuracy rates occurred, and define unexpected questions.

\section{The Applicability of the Cognitive Lie Detection Approach}

The cognitive lie detection approach is predominantly based on the analyses of verbal responses. Of course, verbal analyses can take place only if interviewees talk. To encourage interviewees to talk the cognitive lie detection approach utilises an information-gathering interview style which is, amongst other aspects, characterised by providing opportunities for uninterrupted recall (Meissner, 2011; Meissner et al., 2014). The stereotypical view, often addressed in police manuals (e.g., Inbau et al., 2013), is that suspects are reluctant to talk and that investigators need to use an accusatory approach to get them to talk, characterised by confrontation, and the use of minimisation and maximisation techniques (Kelly, Miller, Redlich, \& Kleinman, 2013; Meissner, 2011; Meissner et al., 2014). The view that an accusatory approach is required is by no means shared by all practitioners. For example, Soufan (2011), an experienced and successful American FBI interrogator who gathered valuable information from al-Qaeda suspects, did not use an accusatory approach when interviewing them. Instead he used an information-gathering approach characterised by rapport building, truth seeking and listening. He also reported in his book the benefit of asking spatial questions for lie detection purposes. In addition, Tedeschini (2012), a Canadian police trainer, also advocates the information-gathering approach. 
Research has shown that the idea that suspects in police interviews are unwilling to talk in information-gathering interviews is a myth rather than fact. A systematic analysis of more than 1,067 such police interviews in the UK has shown that only $5 \%$ of the suspects remained silent (Moston, Stephenson, \& Williamson, 1993). In addition, in his analysis of 600 information-gathering police interviews, Baldwin (1993) found that $80 \%$ of the suspects were thoroughly cooperative and answered police questions of significance. Furthermore, a recent meta-analysis of field and laboratory studies about the influence of the interview/interrogation method on confession outcomes revealed that information-gathering approaches significantly increased the likelihood of true confessions and significantly decreased the likelihood of false confessions compared to accusatory approaches (Meissner, 2011; Meissner et al., 2014). In addition, accusatory approaches significantly increased both true and false confessions compared to control conditions. Moreover, information-gathering approaches elicited significantly more relevant information and significantly more diagnostic cues to deceit than accusatorial methods. In summary, research findings do not back up the idea that suspects are reluctant to talk and that accusatory techniques are needed to yield success in interviews. On the contrary, an information-gathering approach yields better results in obtaining relevant information, obtaining confessions and eliciting cues to deceit.

The lie detection techniques that we have discussed can be employed in various settings. The techniques can be employed to determine the veracity of statements about past activities and future activities (intentions). It has been shown that the unexpectedquestions technique can be employed to identify deceit in both individuals and groups of liars. Future research should examine whether the techniques are sensitive to 
countermeasures, that is, liars' attempts to fool investigators. The unexpected-questions technique should be immune to this, as its method is to ask questions that a liar has not anticipated and therefore not prepared answers for. The number of unexpected questions that can be asked about core elements of the event is vast, which reduces the risk that the unexpected questions become anticipated after some time. However, investigators should be aware that after some time suspects will know which questions are asked, and should change the questions regularly to keep them unexpected. Due to individual differences in people's responses, within-subjects lie detection techniques are preferable because they control for such individual differences. Some of the unexpected-questions techniques are within-subjects techniques.

It is important to note that in the cognitive lie detection studies in which observers made veracity judgements, the observers were never coached about which cues to pay attention to. In other words, it appears that observers pick up these cues naturally and a training program about such cues does not seem to be necessary. Of course, this does not rule out that observers will perform even better if they receive guidance about what to look for. Indeed, Colwell et al. (2009) found that trained observers obtained a significantly higher total accuracy (77\%) than untrained observers (57\%).

\section{Practical Utility of the Findings}

The findings showed that the cognitive lie detection approach produced superior total accuracy rates both with human observers and through an analysis of objective criteria. The finding that human observers also improved their ability to discriminate between truth tellers and liars is important as it demonstrates the potential applicability of the cognitive lie detection approach in real life as practitioners in the field will make 
human-based rather than criteria-based decisions. However, in the lie detection studies included in this meta-analysis -as well as in lie detection studies in general- relative judgements rather than absolute judgements were made. In other words, the results of the meta-analysis indicate that by using the cognitive lie detection technique, $71 \%$ of truth tellers and liars were classified correctly but the findings do not tell us about the accuracy of these techniques in classifying correctly each given individual. However, we can conclude that using the cognitive lie detection approach increases the chance of classifying an individual correctly as being a truth teller or liar. The results also tell us that if practitioners use a cognitive lie detection technique, they will correctly classify more individuals than when they use a standard technique. Or to give an example in a different context, for a professional gambler it would certainly pay off if s/he knew the chances of winning a hand in the long run, despite not being able to be certain about the outcome in any individual game.

Of course, accuracy rates around the $70 \%$ are still quite modest which has implications for real life, for example for clinical use or for mass screening at border controls, where the error rate should be much lower for a lie detection technique to be useful. This point of criticism does not just apply to the cognitive lie detection technique, every veracity assessment tool developed to date encounters this problem (Vrij, 2008).

\section{An Explanation of the Increased Accuracy Rates}

A plausible explanation as to why the cognitive lie detection approach resulted in superior accuracy rates than a standard approach is that the cognitive lie detection approach elicits more and/or stronger (non)verbal cues to deceit. An analysis of the number of cues elicited by a cognitive lie detection or standard technique was not the 
topic of investigation in this meta-analysis. In fact, these 'cues data' are not entirely suitable for a meta-analytic approach. The problem is that different researchers examine different cues, and that, if they use the same cues, they operationalise them sometimes somewhat differently. This makes it difficult to compare the studies with each other. For this reason Vrij, Fisher, Blank, Leal, \& Mann (in press), who reviewed the cues data, presented only a basic documentation and descriptive analyses on the elicited cues to deception. The results showed that cues to deceit were twice as likely to occur when a cognitive lie detection technique was employed compared to a standard technique.

\section{Characteristics of an Unexpected Question}

An important question is how to define an 'unexpected question'. The experiments to date have shown that spatial questions are unexpected, and so are temporal questions and questions about planning. No doubt, many more types of unexpected questions will emerge in future research. Truth tellers and liars will find unexpected questions equally unexpected. The difference between truth tellers and liars emerges in how difficult such questions are for them to answer. Truth tellers should be able to rely on their memory of the event when answering these questions and, if their memory is clear and vivid, will not find the questions too difficult to answer. Liars, however, will not have ready-made answers prepared for these unexpected questions and will find them much more difficult to answer. Furthermore, if liars must create an ad-hoc answer to an unexpected question, they may also have difficulty remembering the answer for the purpose of providing the same answer (consistency) on a later interview.

The key for the unexpected questions technique to work is that truth tellers will know the answer to both expected and unexpected questions. For that to happen, all 
questions should be about central rather than peripheral parts of the event. In that respect, the unexpected-questions technique differs from Levine et al.'s 'strategic questioning' technique (Levine, Shaw, \& Shulman, 2010). In their experiment, some participants cheated on a test and had to deny this in a subsequent interview (liars), whereas other participants did not cheat (truth tellers). 'Strategic' questions about the cheating ('Did any cheating occur?') were compared with 'non-strategic' questions that were unrelated to cheating ('How much experience have you had with doing teamwork activities?'). Observers were better able to detect deceit in the strategic questioning condition. This is probably unsurprising as the non-strategic questions had nothing to do with cheating, and were therefore not about the central part of the event. The question asked in the strategic questioning condition 'Did cheating occur?' was most likely expected by the interviewees, and therefore perhaps not the best question to ask to distinguish between truth tellers and liars.

\section{Conclusion}

All available theories and models about deception acknowledge that lying could be mentally more taxing than truth telling. The new aspect of the cognitive lie detection approach that we propose here is that investigators can magnify the differences in cognitive load experienced between liars and truth tellers, and thereby enhance their ability to detect deception. We hope that this article will stimulate research in this area and will motivate practitioners to employ a cognitive lie detection approach. 


\section{References}

References marked with an asterisk refer to studies included in the meta-analysis.

* Ansarra, R., Colwell, K., Hiscock-Anisman, C., Hines, A., Fleck, R., Cole, L., \&

Belarde, D. (2011). Augmenting ACID with affective details to assess credibility. The European Journal of Psychology Applied to Legal Context, 3, 141-158. Doi:

10.1007/978-1-4614-5547-9_11

Baldwin, J. (1993). Police interview techniques. British Journal of Criminology, $33,325-352$.

Bell, B. E., \& Loftus, E. F. (1989). Trivial persuasion in the courtroom: The power of (a few) minor details. Journal of Personality and Social Psychology, 56, 669-679. Doi: $10.1037 / / 0022-3514.56 .5 .669$

Bembibre, J., \& Higueras, L. (2011). Differential effectiveness of the cognitive interview in a simulation of a testimony. Psychology, Crime, \& Law, 17, 473-489. Doi $10.1080 / 10683160903321540$

Bembibre, J., \& Higueras, L. (2012). Comparative analysis of true and false statements with the source monitoring model and the cognitive interview: Special features of the false accusation of innocent people. Psychology, Crime, \& Law, 18, 913-928. Doi 10.1080/1068316X.2011.589387

* $\quad$ Bogaard, G., Meijer, E. H., \& Vrij, A. (2014). Using an example statement increases information but does not increase accuracy of CBCA, RM, and SCAN. Journal of Investigative Psychology and Offender Profiling, 11, 151-163. Doi: 10.1002/jip.1409 
Bond, C. F., \& DePaulo, B. M. (2006). Accuracy of deception judgements. Personality and Social Psychology Review, 10, 214-234. Doi: $10.1207 / \mathrm{s} 15327957 \mathrm{pspr} 1003 \_2$

Borenstein, M., Hedges, L., \& Rothstein, H. (2007). Meta-analysis: Fixed effect vs. random effects. Meta-analysis.com.

Brand, A., Bradley, M. T., Best, L. A., \& Stoica, G. (2011). Multiple trials may yield exaggerated effect size estimates. Journal of General Psychology, 138, 1-11. Doi: 10.1080/00221309.2010.520360.

Christ, S., E., Van Essen, D. C. Watson, J. M., Brubaker, L. E., \& McDermott, K. B. (2009). The Contributions of Prefrontal Cortex and Executive Control to Deception: Evidence from Activation Likelihood Estimate Meta-analyses. Cerebral Cortex, 19, 1557-1566. doi:10.1093/cercor/bhn189.

* Colwell, K., Hiscock, C. K., \& Memon, A. (2002). Interview techniques and the assessment of statement credibility. Applied Cognitive Psychology, 16, 287-300. Doi: $10.1002 /$ acp. 788

* Colwell, K., Hiscock-Anisman, C., Memon, A., Rachel, A, \& Colwell, L. (2007a). Vividness and spontaneity of statement detail characteristics as predictors of witness credibility. American Journal of Forensic Psychology, 25, 1-26.

* Colwell, K., Hiscock-Anisman, C., Memon, A., Colwell, L., Taylor, L., \& Woods, D. (2009). Training in assessment criteria indicative of deception to improve credibility judgements. Journal of Forensic Psychology Practice, 9, 199-207. Doi $10.1080 / 15228930902810078$. 
* Colwell, K., Hiscock-Anisman, C. K., Memon, A., Taylor, L., \& Prewett, J. (2007b). Assessment criteria indicative of deception (ACID): An integrated system of investigative interviewing and detecting deception. Journal of Investrigative Psychology and Offender Profiling, 4, 167-180. Doi 10.1002/jip.73

Cooper, H. \& Hedges, L. V. (Eds.) (1994). The handbook of research synthesis. New York: Russell Sage Foundation.

Debey, E., Verschuere, B., \& Crombez, G. (2012). Lying and executive control: An experimental investigation using ego depletion and goal neglect. Acta Psychologica, 140, 133-141. Doi:10.1016/j.actpsy.2012.03.004

DePaulo, B. M., Lindsay, J. L., Malone, B. E., Muhlenbruck, L., Charlton, K., \& Cooper, H. (2003). Cues to deception. Psychological Bulletin, 129, 74-118. Doi: 10.1037/0033-2909.129.1.74

Dixon, P. (2008). Models of accuracy in repeated-measures designs. Journal of Language and Memory, 59, 447-456.

Dunlap, W. P., Cortina, J. M., Vaslow, J. B., \& Burke, M. J. (1996). Metaanalysis of experiments with matched groups or repeated measures designs. Psychological Methods, 1, 170-177. Doi.org/10.1037/1082-989X.1.2.170

Egger, M., Smith, G. D., \& Phillips, A. N. (1997). Meta-analysis: Principles and procedures. British Medical Journal, 315, 1533-1537.

* $\quad$ Evans, J. R., Meissner, C. A., Michael, S. W., \& Brandon, S. E. (2013). Validating a new assessment method for deception detection: Introducing a Psychologically Based Credibility Assessment Tool. Journal of Applied Research in Memory and Cognition, 2, 33-41. Doi: 10.1016/j/jarmac.2013.02.002. 
Fleiss, J. L. (1994) Measures of effect size for categorical data. In H. Cooper \& L. V. Hedges (Eds.), The handbook of research synthesis (pp. 245-260). New York: Russell Sage Foundation.

Granhag, P. A., Andersson, L. O., Strömwall, L. A., \& Hartwig, M. (2004). Imprisoned knowledge: Criminals' beliefs about deception. Legal and Criminological Psychology, 9, 103-119. Doi/10.1348/135532504322776889

Granhag, P.A. \& Hartwig, M. (2008). A new theoretical perspective on deception detection: On the psychology of instrumental mind-reading. Psychology, Crime \& Law, 14, 189-200. Doi: 10.1080/10683160701645181

Granhag, P. A., \& Hartwig, M. (2015). The Strategic Use of Evidence (SUE) technique: A conceptual overview. In P. A. Granhag, A. Vrij, \& B. Verschuere (Eds.), Deception detection: Current challenges and new approaches (pp. 231-251). Chichester, England: Wiley.

Granhag, P. A., \& Knieps, M. (2011). Episodic future thought: Illuminating the trademarks of forming true and false intentions. Applied Cognitive Psychology, 25, 274280. Doi 10.1002/acp1674.

Granhag, P. A., Strömwall, L. A., \& Jonsson, A. C. (2003). Partners in crime: How liars in collusion betray themselves. Journal of Applied Social Psychology, 33, 848868. Doi: 10.1111/j.1559-1816.2003.tb01928.x

Haddock, C. K., Rindskopf, D., \& Shadish, W. R. (1998). Using odds ratios as effect sizes for meta-analysis of dichotomous data: A primer on methods and issues. Psychological Methods, 3, 339-353. 
Hartwig, M., Granhag, P. A., \& Luke, T. (2014). Strategic use of evidence during investigative interviews: The state of the science. In: Raskin, D.C., Honts, C.R., Kircher, J.C. (Eds.), Credibility Assessment: Scientific Research and Applications (pp. 1-36). Academic Press.

Hartwig, M., Granhag, P. A., \& Strömwall, L. (2007). Guilty and innocent suspects' strategies during interrogations. Psychology, Crime, \& Law, 13, 213-227. Doi: 10/10683160600750264

Hedges, L. V. \& Olkin, I. (1985). Statistical methods for meta-analysis. Orlando, FL: Academic Press.

Hernandez-Fernaud, E., \& Alonso-Quecuty, M. (1997). The cognitive interview and lie detection: A new magnifying glass for Sherlock Holmes? Applied Cognitive Psychology, 11, 55-68. Doi: 10.1002/(SICI)1099-0720(199702)11:1<55::AID-ACP423>3.0.CO;2-G

Higgins, J. P. T., \& Green, S. (Eds.) (2011). Cochrane handbookfor systematic reviews of interventions (Version 5.1.0). The Cochrane Collaboration (retrieved 18 Sept 2013 from http://handbook.cochrane.org/).

Inbau, F. E., Reid, J. E., Buckley, J. P., \& Jayne, B. C. (2013). Criminal interrogation and confessions, $5^{\text {th }}$ edition. Burlington, MA: Jones \& Bartlett Learning.

Johnson, M. K. (2006). Memory and reality. American Psychologist, 61, 760-771. doi: 10.1037/0003-066X.61.8.760

Johnson, M. K., Foley, M. A., Suengas, A. G., \& Raye, C. L. (1988). Phenomenal characteristics of memories for perceived and imagined autobiographical events. Journal of Experimental Psychology: General, 117, 371-376. doi: 10.1037/0096-3445.117.4.371 
Kelly, C. E., Miller, J. C., Redlich, A. D., \& Kleinman, S. M. (2013). A taxonomy of interrogations methods. Psychology, Public Policy and Law, 19, 165-178. DOI 10.1037/a0030310.

Knieps, M., Granhag, P. A., \& Vrij, A. (2013a). Back to the future: Asking about mental images to discriminate between true and false intentions. The Journal of Psychology: Interdisciplinary and Applied, 147, 619-640.

Knieps, M., Granhag, P.A., \& Vrij, A. (2013b). Repeated visits to the future: Asking about mental images to discriminate between true and false intentions. International Journal of Advances in Psychology, 2, 93-102.

* Köhnken, G., Schimossek, E., Aschermann, E., \& Höfer, E. (1995). The cognitive interview and the assessment of the credibility of adult's statements. Journal of Applied Psychology, 80, 671-684. doi/10.1037/0021-9010.80.6.671

* Lancaster, G. L. J., Vrij, A., Hope, L., \& Waller, B. (2013). Sorting the liars from the truth tellers: The benefits of asking unanticipated questions. Applied Cognitive Psychology, 27, 107-114.

* Leal, S., Vrij, A., Warmelink, L., Vernham, Z., \& Fisher, R. (2015). You cannot hide your telephone lies: Providing a model statement as an aid to detect deception in insurance telephone calls. Legal and Criminological Psychology, 20, 129-146.

DOI: $10.1111 /$ lcrp.12017

Leins, D., Fisher, R., \& Vrij, A. (2012). Drawing on liars' lack of cognitive flexibility: Detecting deception through varying report modes. Applied Cognitive Psychology, 26, 601-607. DOI 10.1002/acp.2837 
* $\quad$ Leins, D., Fisher, R. P., Vrij, A., Leal, S., \& Mann, S. (2011). Using sketchdrawing to induce inconsistency in liars. Legal and Criminological Psychology, 16, 253265. DOI 10.1348/135532510X501775

Levine, T. R., Shaw, A., \& Shulman, H. C. (2010). Increasing deception detection accuracy with strategic questioning. Human Communication Research, 36, 216-231.

* Liu, M, Granhag, P.A., Landström, S, Roos af Hjelmsäter, E., Strömwall, L.A. \& Vrij, A. (2010). “Can you remember what was in your pocket when you were stung by a bee?" - Eliciting cues to deception by asking the unanticipated. Open Criminology Journal, 3, 31-36.

Mac Giolla, E. \& Granhag, P.A. (2014). Detecting false intent among small cells of suspects: Single vs. repeated interviews. Journal of Investigative Psychology and Offender Profiling. Doi: 10.1002/jip. 1419

* Mann, S., Vrij, A., Shaw, D., Leal, S., Ewans, S., Hillman, J., Granhag, P. A., \& Fisher, R. P. (2013). Two heads are better than one? How to effectively use two interviewers to elicit cues to deception. Legal and Criminological Psychology, 18, 324340. Doi 10.1111/j.2044-8333.2012.02055.x

Meissner, C. A. (2011). Evidence-based approaches to forensic interviewing and credibility assessment. Paper presented at the Federal Law Enforcement Training Center, Brunswick, Georgia, US, August 11.

Meissner, C. A., Redlich, A. R., Michael, S. W., Evans, J. R., Camilletti, C. R., Bhatt, S., \& Brandon, S. (2014). Accusatorial and information-gathering interrogation methods and their effects on true and false confessions: A meta-analytic review. Journal of Experimental Criminology, 10, 459-486. DOI: 10.1007/s11292-014-9207-6 
Memon, A., Fraser, J., Colwell, K., Odinot, G., \& Mastroberardino, S. (2010). Distinguishing truthful from invented accounts using reality monitoring criteria. Legal and Criminological Psychology, 15, 177-194. Doi: 10.1348/135532508X401382

* Morgan, C. A. III, Colwell, K., Hazlett, G. (2011). Efficacy of forensic statement analysis in distinguishing truthful from deceptive eyewitness accounts of highly stressful events. Psychiatry \& Behavioral Sciences, 56, 1227-1234. Doi: 10.1111/j.15564029.2011.01896.x

Moston, S. J., Stephenson, G. M., \& Williamson, T. M. (1993). The incidence, antecedents and consequences of the use of the right to silence during police questioning. Criminal Behaviour and Mental Health, 3, 30-47.

* Parker, A. D., \& Brown, J. (2000). Detection of deception: Statement validity analysis as a means of determining truthfulness or falsity of rape allegations. Legal and Criminological Psychology, 5, 237-259. Doi/10.1348/135532500168119

Roos af Hjelmsäter, E., Öhman, L., Granhag, P. A., \& Vrij, A. (2014). Mapping deception in adolescents: Eliciting cues to deceit through an unanticipated spatial drawing task. Legal and Criminological Psychology, 19, 179-188. Doi: 10.1111/j.20448333.2012.02068.x

Rosenthal, R. (1979). The "file-drawer problem" and tolerance for null results. Psychological Bulletin, 86, 638-641.

Shaw, D. J, Vrij, A., Mann, S., Leal, S., \& Hillman, J. (2013). Expect the unexpected? Variations in question type elicit cues to deception in joint interviewer contexts. Applied Cognitive Psychology, 27, 336-343. Doi: 10.1002/acp.2911 
Sooniste, T., Granhag, P.A., Knieps, M., \& Vrij, A. (2013). True and false intentions: Asking about the past to detect lies about the future. Psychology, Crime, \& Law, 19, 673-685. Doi 10.1080/1068316x.2013.793333

Sooniste, T., Granhag, P.A., Strömwall, L.A. \& Vrij, A. (in press). Discriminating between true and false intent among small cells of suspects. Legal and Criminological Psychology. Doi: 10.1111/lcrp.12063.

Soufan, A. H. (2011). The black banners: The inside story of $9 / 11$ and the war against al-Qaeda. New York: W. W. Norton \& Company.

* Suckle-Nelson, J. A., Colwell, K., Hiscock-Anisman, C., Florence, S., Youschak, K. E., \& Duarte, A. (2010). Assessment criteria indicative of deception (ACID): Replication and gender differences. The Open Criminology Journal, 3, 23-30.

Tedeschini, J. (2012). Overcoming roadblocks to reform. Journal of Applied Research in Memory and Cognition, 1, 134-135. Doi:10.1016/j.jarmac.2012.04.008 * Vernham, Z., Vrij, A., Mann, S., Leal, S., \& Hillman, J. (2014). Collective interviewing: Eliciting cues to deceit using a turn-taking approach. Psychology, Public Policy and Law, 20, 309-324. Doi.org/10.1037/law0000015.

Visu-Petra, G., Varga, M., Miclea, M., \& Visu-Petra, L. (2013). When interference helps: increasing executive load to facilitate deception detection in the concealed information test. Frontiers in Psychology, 4, 146. Doi 10.3389/fpsyg.2013.00146.

Vrij, A. (2008). Detecting lies and deceit: Pitfalls and opportunities, second edition. Chichester: John Wiley and Sons.

Vrij, A. (2014). Interviewing to detect deception. European Psychologist, 19, 184-195 Doi: 10.1027/1016-9040/a000201. 
Vrij, A. (2015). A cognitive approach to lie detection. In P. A. Granhag, A. Vrij, \& B. Verschuere (Eds.), Deception detection: Current challenges and new approaches (pp. 205-229). Chichester, England: Wiley.

Vrij, A., Fisher, R., Blank, H., Leal, S., \& Mann, S., (in press). A cognitive approach to elicit nonverbal ane verbal cues of deceit. In J. W. van Prooijen \& P. A. M. van Lange (Eds.), Cheating, corruption, and concealment: The roots of dishonest behavior. Cambridge, England: Cambridge University Press.

Vrij, A., \& Ganis, G. (2014). Theories in deception and lie detection. In: Raskin, D.C., Honts, C.R., Kircher, J.C. (Eds.), Credibility Assessment: Scientific Research and Applications (pp. 301-374). Academic Press.in per

Vrij, A., \& Granhag, P. A. (2012). Eliciting cues to deception and truth: What matters are the questions asked. Journal of Applied Research in Memory and Cognition, 1, 110-117. Doi.org/10.1016/j.jarmac.2012.02.004

Vrij, A., Granhag, P.A., Mann, S. \& Leal, S. (2011). Outsmarting the liars: Towards a cognitive lie detection approach. Current Directions in Psychological Science, 20, 28-32. Doi: 10.1177/0963721410391245

Vrij, A., Granhag, P. A., \& Porter, S. B. (2010). Pitfalls and opportunities in nonverbal and verbal lie detection. Psychological Science in the Public Interest, 11, 89121. Doi: $10.1177 / 1529100610390861$

* Vrij, A., Leal, S., Granhag, P. A., Mann, S., Fisher, R. P., Hillman, J., \& Sperry, K. (2009). Outsmarting the liars: The benefit of asking unanticipated questions. Law and Human Behavior, 33, 159-166. Doi 10.1007/s10979-008-9143-y. 
* Vrij, A., Leal, S., Mann, S., \& Granhag, P. A. (2011). A comparison between lying about intentions and past activities: Verbal cues and detection accuracy. Applied Cognitive Psychology, 25, 212-218. Doi 10.1002/acp.1665.

* Vrij, A., Leal, S., Mann, S., \& Fisher, R. (2012). Imposing cognitive load to elicit cues to deceit: Inducing the reverse order technique naturally. Psychology, Crime, \& Law, 18, 579-594. Doi 10.1080/10683160902776843.

Vrij, A., Leal, S., Mann, S., Vernham, Z., \& Brankaert, F. (2015). Translating theory into practice: Evaluating a cognitive lie detection training workshop. Journal of Applied Research in Memory and Cognition, 4, 110-120.

doi:10.1016/j.jarmac.2015.02.002

* Vrij, A., Leal, S., Mann, S., Warmelink, L., Granhag, P. A., \& Fisher, R. P. (2010). Drawings as an innovative and successful lie detection tool. Applied Cognitive Psychology, 4, 587-594. Doi: 10.1002/acp/1627

* $\quad$ Vrij, A., Mann, S., Fisher, R., Leal, S., Milne, B., \& Bull, R. (2008). Increasing cognitive load to facilitate lie detection: The benefit of recalling an event in reverse order. Law and Human Behavior, 32, 253-265. Doi 10.1007/s10979-007-9103-y. * $\quad$ Vrij, A., Mann, S., Leal, S., \& Fisher, R. (2010). "Look into my eyes”: Can an instruction to maintain eye contact facilitate lie detection? Psychology, Crime, \& Law, 16, 327-348. Doi 10.1080/10683160902776843

Vrij, A., Mann, S., Leal, S., \& Fisher, R. (2012). Is anyone out there? Drawings as a tool to detect deception in occupations interviews. Psychology, Crime, \& Law, 18, 377388. Doi: 10.1080/1068316X.2010.498422 
* Warmelink, L., Vrij, A., Mann, S., Jundi, S., \& Granhag, P. A. (2012). Have you been there before? The effect of experience and question expectedness on lying about intentions. Acta Psychologica, 141, 178-183. Doi.org/10.1016/j.actpsy.2012.07.011

Wiedermann, W., Gula, B., Czech, P., \& Muschik, D. (2011). Correcting overestimated effect size estimates in multiple trials. Journal of General Psychology, 138, 292-299.

* Zimmerman, L. A., Veinott, E. S., Meissner, C. M., Fallon, C., \& Mueller, S. T. (2010). Field Training and Testing of Interview and Elicitation Methods (Final Report prepared under Contract W91CRB-09-C-0082 for US ARMY REDCOM Acquisition Center, Aberdeen Proving Ground, MD). Fairborn, OH: Klein Associates Division of Applied Research Associates.

Zuckerman, M., DePaulo, B. M., \& Rosenthal, R. (1981). Verbal and nonverbal communication of deception. In L. Berkowitz (Ed.), Advances in experimental social psychology, volume 14 (1-57). New York: Academic Press. 


\section{Footnotes}

${ }^{1}$ We opted for using two different effect sizes because one of the reviewers and the third author of this paper could not agree on their relative merits in the context of this meta-analysis. Odds ratios are the recommended type of effect size for categorical data (Fleiss, 1994; Haddock Rindskopf, \& Shadish, et al., 1998), with which we are dealing here (i.e. statements being judged as true or false). Meta-analyses based on odds ratios are very common in the medical sciences, for instance (see Egger, Smith, \& Phillips, 1997; or the Cochrane Handbook, Higgins \& Green, 2011). A weakness of odds ratios is that they do not take dependencies between judgements into account (if the same person makes multiple judgements, for example).

Cohen's $d$ is a more popular and well-known effect size in psychology, but has its weaknesses as well. Specifically, measures of effect size for continuous data (such as Cohen's $d$ ) are suboptimal for the analysis of accuracy data that are based on categorical veracity judgments (true vs. false; Dixon, 2008). Moreover, Cohen's $d$ is inflated if averages are computed across repeated trials within conditions (Brand, Bradley, Best \& Stoica, 2011; Wiedermann, Gula, Czech \& Muschik, 2011), as is the case in some lie detection studies where participants make multiple veracity judgments.

Readers will have their own opinions regarding which approach they find more convincing. To pragmatically resolve the issue here, we use both approaches (as other authors have done, e.g. Bond \& DePaulo, 2006, in their meta-analysis of lie detection accuracy) and present both sets of results. A positive potential effect of this dual approach is that we may have more confidence in the results if the findings obtained with both approaches agree. 
${ }^{2}$ The two approaches differ in one respect: The odds ratio-based analysis shows only a marginal moderator effect for lie detection, whereas this effect is highly significant in the $d$-based analysis. This difference is a consequence of the larger indicated heterogeneity of the lie detection effect sizes in the $d$-based analysis, which is turn a consequence of the fact that one study (Evans et al., 2013) is an extreme outlier in the $d$ based analysis but only a mild outlier in the odds ratio-based approach (which is why we decided to retain it).

${ }^{3}$ Again, the weighted accuracy rates and the moderator analyses showed the same general pattern of results, except for the statistical significance of the moderator effect for lie detection accuracy (see Footnote 2 for an explanation). 
Table 1

Meta-Analytic Results for Total, Truth and Lie Detection Accuracy Using the Standard (Sta) vs. Cognitive (Cog) Approach

\begin{tabular}{|c|c|c|c|}
\hline & \multicolumn{3}{|c|}{ Type of Detection (Number of Included Studies) } \\
\hline & Total (14) & Truth (11) & Lie (11) \\
\hline \multirow{2}{*}{$\begin{array}{l}\text { Detection Accuracy } \\
(\% \text { correct, }[95 \% \mathrm{CI}])^{1}\end{array}$} & Sta: $56[52,60]$ & Sta: $57[52,63]$ & Sta: $47[41,53]$ \\
\hline & Cog: $71[68,75]$ & Cog: $67[62,73]$ & Cog: $67[62,72]$ \\
\hline \multicolumn{4}{|c|}{ Odds ratio-based approach } \\
\hline Effect size $[95 \% \mathrm{CI}]$ & $1.97[1.53,2.52]$ & $1.53[1.09,2.15]$ & $2.38[1.38,4.11]$ \\
\hline Heterogeneity & $\mathrm{Q}(13)=9.56(\mathrm{~ns})$ & $\mathrm{Q}(10)=9.23(\mathrm{~ns})$ & $\mathrm{Q}(10)=23.15 *$ \\
\hline$z(\operatorname{Cog}>$ Sta $)$ & $5.33 * * *$ & $2.47 * *$ & $3.11 * * *$ \\
\hline Fail-safe $\mathrm{N}^{2}$ & 134 & 14 & 29 \\
\hline \multicolumn{4}{|c|}{ Cohen's d-based approach } \\
\hline Effect size $[95 \% \mathrm{CI}]$ & $0.42[0.26,0.58]$ & $0.24[0.08,0.40]$ & $0.53[0.17,0.88]$ \\
\hline Heterogeneity & $\mathrm{Q}(13)=25.33 *$ & $\mathrm{Q}(10)=8.37(\mathrm{~ns})$ & $\mathrm{Q}(10)=44.76 * * *$ \\
\hline$z(\mathrm{Cog}>\mathrm{Sta})$ & $5.04 * * *$ & $2.93 * *$ & $2.92 *$ \\
\hline Fail-safe $\mathrm{N}^{2}$ & 118 & 24 & 24 \\
\hline
\end{tabular}

${ }^{1}$ Sample size-weighted averages. ${ }^{2}$ The number of studies with zero effect sizes needed to render the meta-analytic effect non-significant; calculated after Rosenberg (2005) on the basis of the weighted effect sizes, assuming heterogeneity of effect sizes.

$* p<.05, * * p<.01, * * * p<.001$. 
Table 2

Moderator Analyses of the Impact of Type of Decision-Making (by Human Observers or based on Objective Criteria) on the Effectiveness of Lie Detection Using the Standard (Sta) vs. Cognitive (Cog) Approach

\begin{tabular}{|c|c|c|}
\hline & Truth Detection & Lie Detection \\
\hline \multicolumn{3}{|c|}{ Detection accuracy $(\% \text { correct, }[95 \% \mathrm{CI}])^{1}$} \\
\hline Human Observers $(\mathrm{N}=6)$ & $\begin{array}{l}\text { Sta: } 57[50,63] \\
\text { Cog: } 60[53,67]\end{array}$ & $\begin{array}{l}\text { Sta: } 37[30,44] \\
\text { Cog: } 64[57,71]\end{array}$ \\
\hline Objective Criteria $(\mathrm{N}=5)$ & $\begin{array}{c}\text { Sta: } 58[49,68] \\
\text { Cog: } 80[73,88]\end{array}$ & $\begin{array}{l}\text { Sta: } 66[57,75] \\
\text { Cog: } 73[65,81]\end{array}$ \\
\hline \multicolumn{3}{|l|}{ Odds ratio-based approach } \\
\hline Moderator effect & $Q_{\mathrm{B}}(1)=5.35 *$ & $Q_{\mathrm{B}}(1)=3.25^{(*)}$ \\
\hline Human Observers $(\mathrm{N}=6)$ & $1.18[0.79,1.77]^{2}$ & $3.49[1.45,8.37]$ \\
\hline Objective Criteria $(\mathrm{N}=5)$ & $2.82[1.52,5.23]$ & $1.46[0.81,2.64]$ \\
\hline \multicolumn{3}{|l|}{ Cohen's d-based approach } \\
\hline Moderator effect & $Q_{\mathrm{B}}(1)=4.13 *$ & $Q_{\mathrm{B}}(1)=11.02 * * *$ \\
\hline Human Observers $(\mathrm{N}=6)$ & $0.12[-0.08,0.32]$ & $0.83[0.28,1.38]$ \\
\hline Objective Criteria $(\mathrm{N}=5)$ & $0.47[0.20,0.74]$ & $0.16[-0.11,0.43]$ \\
\hline
\end{tabular}

${ }^{(*)} p<.10,{ }^{*} p<.05, * * * p<.001 . Q_{\mathrm{B}}=$ heterogeneity between factor levels. ${ }^{1}$ Sample sizeweighted averages. ${ }^{2}$ Effect size [95\% confidence interval]. 
Table 3

Moderator Analyses of the Impact of Detection Technique (Imposing Load, Encouraging Interviewees to Say More, Asking Unexpected Questions) on the Effectiveness of Lie Detection Using the Standard (Sta) vs. Cognitive (Cog) Approach

\begin{tabular}{|c|c|c|}
\hline & Truth Detection & Lie Detection \\
\hline \multicolumn{3}{|c|}{ Detection accuracy $(\% \text { correct, }[95 \% \mathrm{CI}])^{1}$} \\
\hline Imposing Load $(\mathrm{N}=5)$ & $\begin{array}{c}\text { Sta: } 56[48,64] \\
\text { Cog: } 58[51,66]\end{array}$ & $\begin{array}{c}\text { Sta: } 34[26,41] \\
\text { Cog: } 63[56,71]\end{array}$ \\
\hline Encouraging Interviewees $(\mathrm{N}=4)$ & $\begin{array}{c}\text { Sta: } 57[46,68] \\
\text { Cog: } 81[72,89]\end{array}$ & $\begin{array}{c}\text { Sta: } 69[59,79] \\
\text { Cog: } 74[66,83]\end{array}$ \\
\hline Unexpected Questions ( $\mathrm{N}=2)$ & $\begin{array}{c}\text { Sta: } 61[48,74] \\
\text { Cog: } 74[62,86]\end{array}$ & $\begin{array}{l}\text { Sta: } 53[39,66] \\
\text { Cog: } 67[54,80]\end{array}$ \\
\hline \multicolumn{3}{|l|}{ Odds ratio-based approach } \\
\hline Moderator effect & $Q_{\mathrm{B}}(2)=6.05 *$ & $Q_{\mathrm{B}}(2)=4.15(\mathrm{~ns})$ \\
\hline Imposing Load $(\mathrm{N}=5)$ & $1.10[0.71,1.71]^{2}$ & $4.04[1.38,11.81]$ \\
\hline Encouraging Interviewees $(\mathrm{N}=4)$ & $3.00[1.51,5.95]$ & $1.40[0.72,2.74]$ \\
\hline Unexpected questions $(\mathrm{N}=2)$ & $1.85[0.81,4.24]$ & $1.79[0.82,3.93]$ \\
\hline \multicolumn{3}{|l|}{ Cohen's d-based approach } \\
\hline Moderator effect & $Q_{\mathrm{B}}(2)=4.65(\mathrm{~ns})$ & $Q_{\mathrm{B}}(2)=14.79 * * *$ \\
\hline Imposing Load $(\mathrm{N}=5)$ & $0.09[-0.13,0.31]$ & $0.94[0.29,1.59]$ \\
\hline Encouraging Interviewees $(\mathrm{N}=4)$ & $0.50[0.19,0.80]$ & $0.14[-0.16,0.43]$ \\
\hline Unexpected questions $(\mathrm{N}=2)$ & $0.29[-0.09,0.67]$ & $0.29[-0.09,0.67]$ \\
\hline
\end{tabular}

$* p<.05, * * * p<.001 . Q_{\mathrm{B}}=$ heterogeneity between factor levels. ${ }^{1}$ Sample size-weighted averages. ${ }^{2}$ Effect size [95\% confidence interval]. 
Appendix 1. Cognitive Lie Detection Studies: Accuracy Rates

\begin{tabular}{|c|c|c|c|c|c|c|c|c|c|c|}
\hline & \multirow[b]{3}{*}{ Studies } & \multicolumn{2}{|c|}{ Sample size } & \multirow{3}{*}{ 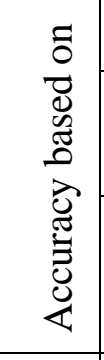 } & \multicolumn{6}{|c|}{ Lie Detection Approach } \\
\hline & & \multirow[b]{2}{*}{ 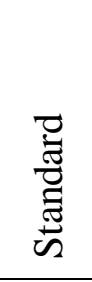 } & \multirow{2}{*}{ 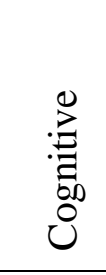 } & & \multicolumn{3}{|c|}{ Standard } & \multicolumn{3}{|c|}{$\begin{array}{c}\text { Imposing } \\
\text { Cognitive Load }\end{array}$} \\
\hline & & & & & 莺 & $\stackrel{9}{\beth}$ & స్ & E & $\cong$ & 흉 \\
\hline (1) & Evans et al. (2013), Study 1 & 46 & 46 & Obs & 55 & 18 & 37 & 59 & 75 & 67 \\
\hline (2) & Vrij et al. (2008) & 24 & 31 & Obs & 50 & 42 & 46 & 56 & 60 & 58 \\
\hline (3) & Vrij, Mann et al. (2010) & 52 & 54 & Obs & 55 & 49 & 52 & 56 & 51 & 54 \\
\hline (4) & Vrij et al. (2012) & 62 & 62 & Cri & -- & -- & 71 & -- & -- & 87 \\
\hline (5) & Vernham et al. (2014) & 30 & 30 & Obs & 53 & 40 & 47 & 73 & 80 & 77 \\
\hline (6) & Zimmerman et al. (2010) & 47 & 47 & Obs & 67 & 18 & 43 & 54 & 63 & 59 \\
\hline & & & & & \multicolumn{3}{|c|}{ Standard } & \multicolumn{3}{|c|}{$\begin{array}{l}\text { Encouraging } \\
\text { Interviewees to } \\
\text { Say More }\end{array}$} \\
\hline (7) & Ansarra et al. (2011) & & & Cri & & & & 67 & 63 & 65 \\
\hline (8) & Colwell et al. (2002) & 50 & 75 & Cri & 67 & 58 & 62 & 84 & 68 & 76 \\
\hline (9) & Colwell et al. (2007a), Exp. 1 & & 58 & Cri & & & & & & 69 \\
\hline (10) & Colwell et al. (2007a), Exp. 2 & & 131 & Cri & & & & & & 75 \\
\hline (11) & Colwell et al. (2009) & & 30 & Obs & & & & & & 67 \\
\hline (12) & Colwell et al. (2007b) & & 38 & Cri & & & & 68 & 89 & 79 \\
\hline (13) & Köhnken et al. (1995) & 30 & 29 & Cri & & & 60 & & & 86 \\
\hline (14) & Leal et al. (2015), Exp 2 & 43 & 40 & Cri & 52 & 73 & 63 & 85 & 75 & 80 \\
\hline (15) & Mann et al. (2013) & 42 & 42 & Cri & 53 & 65 & 59 & 71 & 75 & 73 \\
\hline (16) & Morgan et al. (2011) & & 34 & Cri & & & & 81 & 85 & 83 \\
\hline (17) & Parker \& Brown (2000) & & 28 & Cri & & & & 88 & 92 & 89 \\
\hline (18) & Suckle-Nelson et al. (2010) & & 83 & Cri & & & & 75 & 86 & 80 \\
\hline (19) & Vrij, Leal et al. (2010) & 31 & 31 & Cri & 53 & 88 & 71 & 80 & 88 & 84 \\
\hline & & & & & \multicolumn{3}{|c|}{ Standard } & \multicolumn{3}{|c|}{ Asking } \\
\hline
\end{tabular}




\begin{tabular}{|l|l|c|c|c|c|c|c|c|c|c|}
\hline \multicolumn{2}{|l|}{} & \multicolumn{3}{c|}{$\begin{array}{c}\text { Unexpected } \\
\text { Questions }\end{array}$} \\
\hline$(20)$ & Lancaster et al. (2013) & & 80 & Cri & & & & 78 & 83 & 80 \\
\hline$(21)$ & Leins et al. (2011), Exp. 1 & & 80 & Cri & & & & 80 & 70 & 75 \\
\hline$(22)$ & Leins et al. (2011), Exp. 2 & & 34 & Cri & & & & 100 & 77 & 89 \\
\hline$(23)$ & Liu et al. (2010) & 46 & 46 & Obs & & & 57 & & & 59 \\
\hline$(24)$ & Vrij et al. (2009) & 40 & 40 & Cri & 64 & 53 & 58 & 79 & 65 & 72 \\
\hline$(25)$ & Vrij et al. (2011) & 35 & 32 & Obs & 59 & 53 & 56 & 71 & 68 & 69 \\
\hline$(26)$ & Warmelink et al. (2012) & & 86 & Cri & & & & 69 & 75 & 72 \\
\hline
\end{tabular}

Note. This appendix includes studies comparing the standard and cognitive lie detection approaches as well as studies that use the cognitive lie detection approach only (these studies do not have entries in the 'Standard' columns). Also, where particular experimental conditions within studies have been combined (see notes to individual studies below), the means and effects sizes have been recalculated, using the raw data where possible. The sample sizes are total sample sizes (i.e. aggregated across truth and lie detection conditions; further breakdowns are available from the authors upon request). Obs $=$ Human observers, $\mathrm{Cri}=$ Criteria-based veracity classification .

Individual studies: (1) Evans, Michael, Meissner, \& Brandon (2013). In Study 1, students watched four video clips (of 2 liars and 2 truth tellers). Study 2 was not included because cognitive load was not manipulated but inferred from language proficiency. (2) Vrij, Mann, Fisher, Leal, Milne, \& Bull (2008). Observers (in Exp. 2; British police officers) watched 12 video clips (6 liars and 6 truth tellers from Exp. 1). (3) Vrij, Mann, Leal, \& Fisher (2010). Observers (in Exp. 2) watched/listened to video/audiotapes (showing 8 liars and 8 truth tellers each from Exp. 1). The 'video and audio' and 'audio' conditions are combined. (4) Vrij, Leal, Mann, \& Fisher (2012). Pairwise veracity 
classifications based on the amount of detail elicited for 2 statements ( 1 true, 1 false) by the same interviewee, using either chronological order (= standard) or reverse order (= cognitive) questions. (5) Vernham, Vrij, Mann, Leal, \& Hillman (2014). Observers in Exp. 2 read one transcript each (from 1 liar or 1 truth teller in Exp. 1); comparison between non-turn taking condition (condition 1) and turn-taking condition examining the turn-taking cues (condition 3). (6) Zimmerman, Veinott, Meissner, Fallon, \& Mueller (2010). Interviewers made veracity judgements based on standard approach and cognitive approach interviews. (7) Ansarra, Colwell, Hiscock-Anisman, Hines, Fleck, Cole, \& Belarde (2011). Reality Interview. (8) Colwell, Hiscock, \& Memon (2002). Criteria-based veracity classification, cognitive and inferential interviews combined (using the results reported in their Table 4; classified cases only). (9) Colwell, Hiscock-Anisman, Memon, Rachel, \& Colwell (2007) Experiment 1. Cognitive Interview. (10) Colwell, Hiscock-Anisman, Memon, Rachel, \& Colwell (2007), Experiment 2. Cognitive Interview. (11) Colwell, Hiscock-Anisman, Memon, Colwell, Taylor, $\&$ Woods (2009). Cognitive interview, observers read transcripts, untrained and trained judges combined. (12) Colwell, Hiscock-Anisman, Memon, Taylor, \& Prewett (2007). Reality Interview, initial recall and follow up questions combined. (13) Köhnken, Schimossek, Aschermann, \& Höfer, (1995). Standard interview versus cognitive interview, CBCA-based classification results only (see Table 5 in Köhnken et al., 1995). (14) Leal, Vrij, Warmelink, Vernham \& Fisher (2015). Standard interview versus model response interview (Exp. 2). (15) Mann, Vrij, Shaw, Leal, Ewens, Hillman, Granhag, \& Fisher (2013). Neutral interviewer (= standard approach) vs. supportive interviewer (= cognitive lie detection approach) conditions; suspicious interviewer condition excluded. Objective and subjective detail scores combined for veracity classification. (16) Morgan, Colwell, \& Hazlett (2011). First and second account combined. (17) Parker \& Brown (2000). CBCA results only, unsubstantiated cases (i.e. neither clearly true nor false) excluded. (18) Suckle- Nelson, Colwell, Hiscock-Anisman, 
Florence, Youschak, \& Duarte (2010). Initial recall and follow up questions combined. (19) Vrij, Leal, Mann, Warmelink, Granhag, \& Fisher (2010). Veracity classification based on whether agent was included in text (= standard approach) or drawing (= cognitive lie detection approach). (20) Lancaster, Vrij, Hope, \& Waller (2013). (21) Leins, Fisher, Vrij, Leal, \& Mann (2011), Experiment 1. (22) Leins, Fisher, Vrij, Leal, \& Mann (2011), Experiment 2. (23) Liu, Granhag, Landström, Roos af Hjelmsäter, Strömwall, \& Vrij (2010). Students in Exp. 2 watched video clips of children's (true or false) statement from Exp. 1. The children had been asked anticipated (= standard) versus unanticipated (= cognitive lie detection) questions. (24) Vrij, Leal, Granhag, Mann, Fisher, Hillman, \& Sperry (2009). Results collapsed across delay variable. General questions score (= standard approach) versus spatial, temporal and drawing scores combined (= cognitive lie detection approach). (25) Vrij, Leal, Mann, \& Granhag (2011). Students in Exp. 2 read transcribed statements (1 truthful, 1 deceptive) from military/police officers in Exp. 1. Past activities (Condition 1 in Exp. 2 = standard approach) versus intentions (Condition 2 = cognitive lie detection approach) comparison. Condition 3 (past activities and intentions) was excluded. (26) Warmelink, Vrij, Mann, Jundi, \& Granhag (2012). 